\title{
Preference for Reference
} New Options and Choices for Academic Library Users

\section{Diane Granfield and Mark Robertson}

Diane Granfield is a Librarian at Ryerson University in Toronto. Mark Robertson is a Librarian at York University in Toronto. Submitted for review April 25, 2006; accepted for publication February 16, 2007.
Reference \& User Services Quarterly, vol. 48 , no. 1 , pp. $44-53$ (c) 2008 American Library Association. All rights reserved. Permission granted to reproduce for nonprofit, educational use.
This exploratory study investigated the help-seeking preferences of library users at two large urban universities in Toronto. Reference desk and virtual reference users were compared in terms of their perceptions of the options now available for obtaining reference help. The premise for the study was based on the assumption that a reasonable exposure to newer reference services, such as chat and email, had occurred, therefore allowing for an examination of emerging preferences for different types of services. Surveys were distributed to both reference desk and virtual reference users asking seven core questions exploring use and preference for reference services as well as habits and preferences for study location (in library, off campus, etc.). The results suggest that the reference desk continues to be the most popular method of getting help in the library, but virtual reference satisfies a niche for users who prefer to work outside the library. Those who use virtual reference tend to perceive their options for getting help differently from other users. Virtual reference users do not perceive virtual reference as a novelty or as a marginal service, but see it as a significant service option. In addition, the results show that virtual reference services may have a special appeal to graduate students since graduate students seem more likely to conduct their research outside the library. The study concludes with recommendations for planning and for future research.

"He not busy being born is busy dying." -Bob Dylan

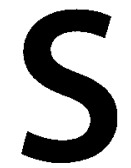
ince the early 1990s, reference services have been in a period of decline and rebirth. The term "transitional" is often used to describe the service culture, the processes, and the technologies involved in providing reference assistance. Along with staggering increases in digital content, we have seen the emergence of a generation of new students who have grown up "native" in a technologically intense world, the rise of distance education and distributed course delivery, the development of the learning commons model; an eclectic student body made up of more nontraditional learners; and we have seen the decline in use of traditional reference services. ${ }^{1}$ Prensky, in his essay "Digital Immigrants, Digital Natives," argues that our era is a uniquely pressured one:

Today's students have not just changed incrementally from those of the past, nor simply changed 
their slang, clothes, body adornments, or styles, as has happened between generations previously. A really big discontinuity has taken place. One might even call it a "singularity" - an event which changes things so fundamentally that there is absolutely no going back. This so-called "singularity" is the arrival and rapid dissemination of digital technology in the last decades of the 20 th century. ${ }^{2}$

Reference librarians have considered and studied these wide-ranging transformations-the demographics, technological pressures, and the changing educational climate-and have experimented with and adopted new approaches to service. As Crowe noted, "While WHAT reference librarians do is not so different-we still assist users in finding and evaluating information, provide instruction in using resources, and select materials- HOW we do it, however, and the tools and resources we use have changed dramatically."

One of the most significant developments in reference services these past several years has been the emergence of real-time virtual reference (VR). VR for the purposes of this study is defined as a synchronous, real-time exchange "where patrons employ computers or other Internet technology to communicate with reference staff, without being physically present.". The terms "VR" and "chat reference services" will be used interchangeably. The emphasis in our study is on real-time or synchronous services (as opposed to other electronic services by asynchronous methods, such as e-mail reference).

VR services generally began to emerge in the early 2000 s. The advent of VR was greeted by much of the library community with great optimism and a spirit of experimentation. More recently, the enthusiasm for chat services has been tempered by persistent technological challenges and questions regarding cost-effectiveness. At the same time, the community has matured to grapple with issues concerning the development of service standards and performance measures, as well as calls to adopt a comprehensive research agenda. ${ }^{5}$ One particularly noteworthy sentiment that struck a chord was voiced by Steve Coffman, one of the early and influential proponents of VR, when he questioned the ongoing relevance of synchronous Web-based services in late $2004 .{ }^{5}$ An important debate has emerged regarding the efficacy of VR compared to telephone, e-mail, and hybrid services.

We have been involved in a VR collaboration since 2001 among three Ontario universities. Catering to a student body of close to ninety thousand, we have witnessed the service grow in popularity. Despite the popularity of VR at our universities, questions regarding its cost-effectiveness persist. We continue to face questions about such issues as the length of time required to answer questions and the inconsistent performance of software and staffing models.

Like most North American academic libraries, we had experienced gradual declines in usage at our reference desks since the early 1990s. Because of the significant changes of the past decade, the decision to introduce VR services was, from our perspective, a logical, appropriate, and progressive response. A successful pilot phase segued into a relatively stable service. After four years of both e-mail and chat services, we felt the time was ripe to consider reference services in a comparative light and begin to explore, through surveys and other means, answers to the essential question, what is the best combination of services for our users when they need help? We were interested in "looking more closely at how users are dealing with their information problems and how they get help from reference librarians in technological environments." "7

Our study represents a preliminary exploration of the help-seeking preferences of a student body that increasingly prefers to be off-site using digital resources, away from the library, and for a variety of reasons is less likely to use the physical reference desk. Specifically, we were interested in exploring how users prefer to get help when on campus versus off campus, their preference for location when doing research, and the differences between reference desk users and users of our VR services. Basically, we were concerned with contributing to "informed decisions about space, services, and resources [by not only understanding] ... the types of information that are being sought, but also the environment that the user is most comfortable [with] - either physical or virtual or some combination."

\section{LITERATURE REVIEW}

Since the early 2000s the burgeoning literature relating to VR has for the most part taken the form of case studies, commentary, and anecdotes. ${ }^{9}$ The empirically based literature is small but growing. A review of the empirical literature indicates that few studies have been conducted to tell us how changes in technology have informed or should inform reference services and, specifically, how these changes in technology have affected users' help-seeking behaviors and preferences.

Massey-Burzio intimated this as far back as 1998 and called for more responsiveness "to actual user needs and preferences... [i]nstead of wasting time insisting on the value of delivering reference services the way we always have."10 Ten years later, the study of user preferences within the reference service milieu has continued to receive little attention. Library users have ever-increasing amounts of digital content at their fingertips, and many studies show they prefer this format over print. "' That much we know. However, the literature provides a limited view of what users prefer to do in this environment when they need assistance. There have been no connections made in studies between preference for format and preference for obtaining assistance.

Thus, help-seeking preference studies or studies that compare different reference services are in somewhat uncharted territory. The focus of the literature review was to find studies of VR that looked at descriptive indicators of these services in a comparative light. Three strains of literature emerged: studies that compare the use of different types of reference services from a user perspective; studies of what 


\section{FEATURE}

users actually prefer to do when they need assistance with library research; and studies of preference for location when doing research.

\section{Comparative Studies}

Motivated by research on library anxiety and related studies, Ruppel and Fagan were interested in exploring whether a reference service using instant messaging (IM) software to chat with students would solve some users' aversion to the desk. ${ }^{12}$ Their review of more than three decades of literature has shown us that "many patrons chose not to ask for help because they are or expect to be dissatisfied, embarrassed, or do not believe librarians are ready or willing to help them. ${ }^{13}$ They surveyed 340 users with the intention of comparing perceptions of VR with the physical reference desk. Their results revealed much about student experiences with the two modes of assistance. Users indicated that the top advantage of the IM reference service was convenience and not having to get up from their workstation or give up their computer, and 15 percent of the users liked the anonymity. An astonishing 29 percent thought staff did not look helpful at the physical reference desk and 17 percent did not want to go to the library building to do their research. In spite of these negative perceptions, the physical reference desk had a clear advantage for most users because of the "personal touch."

Foley conducted a survey (with a relatively small return rate) that asked users why they used Internet messaging rather than visiting, telephoning, or e-mailing reference staff. ${ }^{14}$ Though this study did not extrapolate about choice-making, it did hint at some of the reasons why IM may be preferred over other modes of reference: convenience, phone reference is a hassle, the user can't be online at the same time as they receive help, they are not on campus often, and they liked the instantaneous nature of the exchange.

Nilsen conducted a study that looked at perceptions of the service received at the virtual reference desk and the physical reference desk. ${ }^{13}$ The research involved library science students posing as users and then filling out a detailed questionnaire after each "visit" to a physical and VR desk. One interesting dicovery was that if students were not familiar with chat technology (such as MSN Messenger or Yahoo! Messenger), they tended to prefer e-mail reference over VR. The reason noted for this was that a lack of familiarity may lead to a sense of intimidation or resistance. Nearly everyone became enthusiastic about chat reference service, and preferred it to e-mail, once they had used it. A final and unfortunate conclusion was that the physical reference desk and the VR desk gave "equally poor service." This conclusion was based on data involving the reference interview (or lack thereof). Though a discussion of the quality of the reference interaction is beyond the scope of this article, such a study would provide some insight into what users might prefer to do to get help through the lens of service quality and satisfaction measures: an important consideration for future research.
Stoffel and Tucker compared e-mail and chat to determine user perceptions of their services as a means to improve reference services. ${ }^{16}$ They surveyed patrons following their use of the services and admittedly had low response rates, particularly from chat reference users. That said, some of the conclusions are useful for our purposes. While they did not ask questions regarding preference explicitly, they did ask users if they used other services in tandem to meet their information needs-at least with regards to the specific questions each user posed. Fewer than one in ten used another service in the case of e-mail users; chat user responses to this question were not noted in the article. Stoffel and Tucker concluded that there was high satisfaction for their virtual services and that e-mail users were slightly more satisfied than chat users.

\section{Use Studies and Library Visits Studies}

In the face of claims that synchronous Web-based reference services are here to stay, Frederiksen, Cummings, and Ursin asked whether it was reasonable to claim that library users "expect, or will use, online help delivered by a library Web site." ${ }^{17}$ Surveys were administered to the general university population as well as to users of the reference desk asking questions regarding the use of chat software (AOL Instant Messenger, Yahoo! Messenger, or MSN) for chat and preferred chat features. They also asked the users whether they would think of using chat for research help, and a final question on whether they had heard of the library's Ask a Librarian chat service. Questions were not asked about the respondents' current use of any of the library's other reference services. Their survey attempted to find whether there is a connection between use of chat and a possible link to comfort and openness to a library chat service. Sixty-one percent of people who do not chat would nevertheless consider using chat for research help. Eighty-three percent of respondents were not aware of the chat reference service. The authors concluded that marketing the chat service would be well worth the effort. They also mused about the potential problems of widespread adoption; the perception of chat as a frivolous leisure activity, for example, presents a marketing challenge for a serious library service.

A needs assessment survey was conducted at the University of Maryland University College (UMUC) by Kelley and Orr to examine trends in student use of the library and its resources and services. ${ }^{18}$ This survey is of particular interest because of its focus on comparing and contrasting different types of users-students taking online course versus in-classroom students, undergraduate versus graduate students-and because of its various cross-tabulations with print and electronic resource preferences. UMUC has an interesting demographic because it has a high proportion of distance education students and so signals characteristics of a population that is more dependent on remote services and digital content. Only 32 percent of the respondents had visited the library in the past year and they were more likely to visit the library if 
they were studying in a classroom. While the study did not ask about reference services per se, respondents indicated that "access to staff' was significantly less important than a number of other library offerings, such as access to electronic resources and off-campus access to the catalogue.

The study that bears some similarity to the present research was conducted by Johnson, who performed a survey to investigate "university affiliates' awareness of, use of, and interest in reference services, with a particular focus on online chat reference (synchronous digital reference)." ${ }^{19}$ The survey instrument asked directly for "their first option" if seeking assistance from library staff in a hypothetical scenario, and relationships were drawn between preferences noted and status of respondent. It was found that undergraduates were most likely to choose face-to-face reference services and faculty were more likely to prefer e-mail. Few people had used the chat service and few people were even aware of it. Of the three people that used chat, only one said they would use it again. This particular campus had only one year's experience with VR, and it is not surprising that marketing and promotion formed an important part of their conclusions.

\section{METHODOLOGY}

This study consisted of two surveys, one in-person and one online, carried out during the fall of 2004. The surveys were distributed to library users at two universities in Toronto: Ryerson University with a full-time equivalent (FTE) student population of eighteen thousand and York University with a student body of thirty-eight thousand (FTE). Both universities are located in a large urban environment and most of the students reside off campus. Ryerson and York Universities, as noted previously, have been collaborative partners providing a chat reference service since 2001. The service has provided text-based interactions with page pushing and sharing, and co-browsing of licensed databases.

The premise for the study was based on the notion that a reasonable exposure to newer reference services like VR had occurred (both universities provide e-mail services). By issuing a survey, we could shed some light on emerging preferences for different types of service and whether there are different preferences depending on exposure to the VR service and preference for study location. The research reported here is considered exploratory and not intended to be representative.

A pop-up survey was provided to all VR users over a three-week period in November 2004 and appeared following the close of a session with a librarian; the same questions were issued in print to reference desk users over the same time period. Basically, the surveys were distributed until an acceptable amount had been filled out: approximately one hundred for each university's reference desks and approximately one hundred in total from VR users. The final frequencies for each survey were reference desk, 242 and VR, 106. The survey (see appendix) asked seven core questions exploring use and preference for reference services and habits and preferences for study location (in library, off campus, etc.) as well as resources and chat software use.

The sample sizes for each service point were not proportionate to actual reference desk and VR statistics during this time period. During the same period our two universities jointly had 382 VR sessions and approximately 9,500 Reference Desk interactions. ${ }^{20}$ As it turned out, it was much easier to obtain feedback using a pop-up survey after a VR session, than to ask users in person at the reference desk. The return rate for our VR users during that period of time was approximately 28 percent. For the desk survey, the staff handed out surveys to users at the end of a reference interaction. Although all staff at the reference desks were aware of the study, they were not always able to hand them out consistently (this could have been for a number of reasons:e.g., staff would often forget or be too busy). Consequently, we cannot calculate the return rate of the reference desk surveys. Our purpose, however, was to obtain enough data to compare VR and reference desk users, not to sample the larger academic communities of our universities; and our main concern was to obtain enough data to ensure that smaller groups, like graduate students, would be adequately represented. The amount of data that would have resulted from a random sampling of our university populations would not have been adequate to describe our VR users. For example, Johnson sampled the entire university population, and of that sample only 3 percent had used the chat service. ${ }^{21}$

The intent was to be able to explore VR and desk users in terms of their preferences and behavior. While this type of sampling does not allow for statistical significance testing (a Chi square, for example), the sample size provided some latitude for analysis and speculation as well as the opportunity to suggest directions for further study The focus of the study was primarily in the comparison of preferences of our two user groups. We compared the status (undergraduate, graduate students, staff, and so on) of these two user groups, but this study did not undertake a thorough analysis of other characteristics such as age, gender, and commuting distance.

\section{Focus Groups}

Four focus groups were conducted following the survey in the winter of 2005. They were carried out both in person and online. The purpose was to gain qualitative insight into some of the issues that arose from the survey results and to assist us in defining directions for future study The online focus groups were made possible through the Meeting Room function of our Tutor.com VR software. Each focus group was given seven questions relating to help-seeking preferences, problems encountered when getting help, expectations of the chat reference service, and suggestions for improvement of the chat service. Seven volunteers for the in-person groups and four for the online groups took part in the focus groups. This anecdotal evidence will be noted in the discussion section. 


\section{FEATURE}

\section{Results}

Surveys were completed by 348 library users. Of these, 106 (30 percent) were completed by VR users, and 242 (70 percent) were completed by reference desk users. The proportion by institution differed between the two types of surveys. Because York University's VR service is busier than Ryerson's, the majority of the VR surveys were completed by York users. Seventy-five percent were York users, 22 percent were Ryerson users, and the remaining 3 percent were unaffiliated with either institution. The proportion was more even for the surveys completed at a reference desk; 53 percent of these were York surveys and 47 percent were Ryerson surveys.

Respondents were asked what their current status was at the university (table 1). The response to this question differed considerably between the two surveys. In both cases the respondents were largely undergraduates $(74.5$ percent of the VR respondents, and 86.4 percent of the reference desk respondents). The real difference lay in the proportion of graduate students: 16 percent of the VR respondents were graduate students, compared to a mere 3.3 percent of the reference desk respondents. Very few VR respondents identified as continuing education students, but 6.2 percent of the reference desk respondents identified as such. The numbers of faculty and university staff were under 2 percent.

Reference desk and VR users were asked two questions on their preferences for obtaining research help. Ratings were on a scale of 1 to 5 , where 1 was the least preferred, and 5 was the most preferred. Respondents were first asked about preference for getting help when in the library (table 2), and then asked for preferences when off campus (table 3). It was considered wise to divide the question into two separate questions, since options are clearly different depending on location. Among the response options, consulting information on the library website was included as well as searching Google or another Internet search engine. These options were included because it was felt that our users may increasingly seek answers to what would be reference questions by employing self-help strategies and consulting sources on the Internet (whether they are sites we have constructed ourselves or popular external sites). These two questions allowed for comparing preferences for obtaining help between the reference desk group and the VR group.

The traditional reference desk has the highest in-library preference rating for both groups (desk users rating $=4.4$; VR users rating $=4.3$ ). Surprisingly, our library websites seem to be the next highest rated option for getting research help (desk $=3.8 ; \mathrm{VR}=3.5$ ). E-mail and telephone reference options were rated relatively low by both reference desk and VR users, although these services were rated slightly lower by the VR respondents. For the most part, the reference desk and the VR results were very similar in their ratings. The only rating in which there was a notable difference between the two groups of respondents was in the rating for the use of VR when seeking help from within the library. The VR respondents rated virtual reference 3.5 (roughly the same as the library website),
Table 1. Status of Respondents

\begin{tabular}{lllll}
\hline & \multicolumn{2}{l}{ Desk Survey } & \multicolumn{2}{l}{ VR Survey } \\
& No. & $\%$ & No. & $\%$ \\
Undergrads & 209 & 86.4 & 79 & 74.5 \\
Graduate & 8 & 3.3 & 1.7 & 16 \\
Cont. Ed. & 15 & 6.2 & 3 & 2.8 \\
Faculty & 2 & 0.8 & 3 & 2.8 \\
Staff & 3 & 1.2 & 2 & 1.9 \\
Other & 1 & 0.4 & 2 & 1.9 \\
N/A & 4 & 1.7 & 0 & - \\
Total & 242 & 100 & 1.06 & 99.9 \\
& & & &
\end{tabular}

Table 2. If You Are In One of the Libraries, How Would You Prefer To Get Research Help? (on a scale of 1-5, where $1=$ least preferred, $5=$ most preferred)

\begin{tabular}{lll}
\hline & $\begin{array}{l}\text { Desk Survey } \\
\text { Averages }\end{array}$ & $\begin{array}{l}\text { VR Survey } \\
\text { Averages }\end{array}$ \\
Reference Desk & 4.4 & 4.3 \\
Telephone Reference & 2.0 & 1.8 \\
Virtual Reference & 2.2 & 3.4 \\
E-mail Reference & 2.2 & 2.0 \\
Library Website & 3.8 & 3.5 \\
Google/Search Engine & 3.6 & 2.8 \\
Other & 2.0 & 1.8
\end{tabular}

Table 3: If You Are Off Campus, How would You Prefer To Get Research Help? (on a scale of $1-5$, where $1=$ least preferred, $5=$ most preferred)

\begin{tabular}{lll}
\hline & $\begin{array}{l}\text { Desk Survey } \\
\text { Averages }\end{array}$ & $\begin{array}{l}\text { VR Survey } \\
\text { Averages }\end{array}$ \\
Telephone Reference & 2.6 & 2.9 \\
Virtual Reference & 2.6 & 4.3 \\
E-mail Reference & 2.9 & 3.1 \\
Library Website & 4.3 & 3.7 \\
Google/Search Engine & 3.9 & 3.1 \\
Other & 2.4 & 1.9
\end{tabular}

whereas the desk respondents rated it only 2.2 (on par with the ratings of e-mail and telephone reference). It appears 
Table 4. Preference for Research Location when Doing an Assignment -Desk vs. VR Users

\section{Desk Survey (\%) VR Survey (\%)}

\begin{tabular}{|c|c|}
\hline Library & 60.7 \\
\hline $\begin{array}{l}\text { On Campus, not in } \\
\text { Library }\end{array}$ & 4.7 \\
\hline Off Campus & 24.8 \\
\hline No Preference & 9.8 \\
\hline Total & 100 \\
\hline
\end{tabular}

Table 5. In the Past Twelve Months, How Often Have You Visited One of the Libraries? Desk vs. VR Users

\begin{tabular}{lll}
\hline & Desk Survey (\%) & VR Survey (\%) \\
Never & 0 & 2.9 \\
A Few Times & 21.9 & 17.6 \\
About Once a Week & 8.9 & 20.6 \\
Once a Week & 18.6 & 22.5 \\
$\begin{array}{l}\text { Several Times a } \\
\text { Week }\end{array}$ & 50.6 & 36.3 \\
Total & 100 & 99.9
\end{tabular}

Table 6. Preference for Research Location when Doing an Assignment-Undergraduate vs. Graduate Students

\begin{tabular}{llcll}
\hline & \multicolumn{2}{l}{$\begin{array}{l}\text { Undergraduate } \\
\text { Students }\end{array}$} & \multicolumn{2}{l}{ Graduate Students } \\
& $\%$ & No. & $\%$ & No. \\
Library & 43.8 & 173 & 25 & 8 \\
On Campus, & 4.1 & 16 & 18.8 & 6 \\
Not In Library & & & & \\
Off Campus & 33.9 & 134 & 40.6 & 13 \\
No Preference & 12.2 & 48 & 12.5 & 4 \\
No Response & 6.1 & 24 & 3.1 & 1 \\
Total & 100.1 & 395 & 100 & 32
\end{tabular}

that virtual reference users see the service as a benefit in the library, and not just off campus.

When considering off-campus options for obtaining help with research, the reference desk respondents gave the highest preference ratings to the library websites (4.3) and Google or other Internet search engines (3.9). These selfhelp options were not rated as highly by the VR respondents.
Instead, the VR group not surprisingly rated virtual reference highest (4.3). In fact, the VR group rated the VR service as high as an off-campus option as they rated the reference desk as an in-library option. The reference desk respondents did not rate VR very highly (2.6). In fact, the reference group respondents rated VR even lower than they rated e-mail and telephone reference services (which rated only 2.9 and 2.6, respectively). E-mail and telephone services also rated low in preference for the VR group (3.1 and 2.9, respectively). Again, the most dramatic difference between the two groups was in the preference ratings for virtual reference off-campus. The other interesting pattern was that the VR group gave lower ratings to self-help options (the library website and Internet search engines) than the reference desk group.

Respondents were also asked where they most prefer to do research when working on an assignment (table 4). The preferences for research location were dramatically different for the reference desk and VR survey groups. Of the reference desk respondents, 60.7 percent prefer to conduct research in the library, while only 25.7 percent of VR respondents prefer to work in the library. The preferences are reversed for working off campus. Only 24.8 percent of desk users prefer working off campus, while 55.4 percent of the VR group said they preferred working off campus. Very few people of either group expressed a preference for working in nonlibrary spaces on campus.

The findings on preference for research location were bolstered by the results of the question regarding how often patrons visit one of the libraries at their institution. The results (table 5) clearly show that users of VR are much less likely to visit the physical library than the patrons who use the reference desk. This is not altogether surprising given that patrons who filled out the survey at the reference desk are already in the library (hence the 0 percent for reference desk survey respondents who have never visited the library), and therefore more likely to use the library. Conversely, VR services seem to be used by patrons who are less likely to be in a position to use our on-site services.

The responses of undergraduate and graduate students were compared on several questions. We wanted to see if graduate students were more or less likely than undergraduates to use the library on-site, and if these two groups had different preferences for obtaining research help. Table $6 \mathrm{com}-$ pares undergraduate and graduate students on the question of where they prefer to do research. Although we did not have a significant number of graduate student respondents (only thirty-two), the data suggest that graduate students prefer to conduct research outside of the library buildings, whether that be elsewhere on campus (18.8 percent) or off campus (40.6 percent). A much larger proportion of the undergraduate respondents ( 43.8 percent) preferred to conduct their research within one of the campus libraries.

A different pattern was noted between undergraduate and graduate students when results were compared for the question of how they would prefer to get research help when off campus. Table 7 shows a comparison of the average ratings. 


\section{FEATURE}

VR was rated higher by graduate students (3.3) than by undergraduate students (2.9). It also appears that undergraduates rely on self-help strategies (the library website or Internet search engine) more than graduate students.

\section{DISCUSSION}

In both surveys, undergraduates are overwhelmingly represented, yet graduate students are clearly a larger group proportionately in the VR survey sample than in the reference desk sample ( 16 percent of VR users surveyed, and 3.3 percent of reference desk users surveyed). It is important to note that graduate students, in real numbers, represent only thirty-four respondents; however, these results are consistent with other data collected by our institutions that also point to the popularity of the service among graduate students. Over the last year and a half, 10 percent of York University's VR users have logged in as graduate students. (We were unable to obtain comparable data from our reference desks.)

The data also reflects what we know about graduate students in terms of study habits and privileges: They have more options in and around campus to study and have longer loan periods, making visits less necessary on a regular basis. This preference by graduate students to work outside the library was confirmed by the current survey. It is therefore not surprising that graduate students rated VR higher in terms of preference than undergraduates, since VR can help accommodate the needs of off-campus library users. Graduate students' help-seeking preferences may also reflect a clearer awareness of service options, and it may be that they are more sophisticated users because they have had more exposure to library resources and services. Although our graduate data set is small, it suggests that VR may suit the needs of graduate students in a way that the physical reference desk may not.

This is an interesting result and one that is consistent with other studies that show differences in information-seeking behavior and preferences between faculty, graduate students, and undergraduates ${ }^{22}$ Johnson's data, for instance, also showed there to be slightly more interest for chat services among graduate students than among the other populations sampled. ${ }^{23}$ Precisely what this means in the current focus of help-seeking behavior is not known. Further study on this is needed.

The reference desk is rated highest by both VR and reference desk user respondents. This is consistent with findings by Ruppel and Fagan, and this was confirmed by the focus group participants who see the reference desk as the premier reference service offered by their libraries and who see the face-to-face personal encounter with a staff member as desirable. ${ }^{24}$ Surveyed desk users and VR users alike have moderate to low interest in telephone and e-mail reference services, but both see the library's website and Internet search engines as options for research support. However, for desk survey respondents, choosing the library's website and Internet search engines for off-campus assistance could be indicative of a lack of awareness of off-site options for help. After all, VR users
Table 7. Preference for Getting Help off CampusUndergraduate vs. Graduate Students (averages from a scale of $1-5$, where $1=$ least preferred, $5=$ most preferred)

\section{Undergraduate Graduate Students Students}

$\begin{array}{lcc}\begin{array}{l}\text { Telephone } \\ \text { Reference }\end{array} & 2.6 & 2.9 \\ \text { Virtual Reference } & 2.9 & 3.3 \\ \text { E-mail Reference } & 2.8 & 2.9 \\ \text { Library Website } & 4.3 & 4.0 \\ \begin{array}{l}\text { Google/Search } \\ \text { Engine }\end{array} & 3.8 & 3.0\end{array}$

appear to rely somewhat less on the self-help strategies of searching the library websites or Internet search engines. VR users show a preference for chat reference when either on or off campus, a preference comparable to their preference for the desk. All but one of the focus group subjects (all were VR users) preferred VR when off campus. The one exception preferred the phone.

The unfavorable rating for e-mail and telephone, particularly telephone reference, is worrisome. Most libraries have policies that position telephone reference as a lower priority to in-person reference. At many academic institutions, telephone service continues to be staffed from the reference desk (unlike chat and e-mail reference services) but does not receive the same level of service. This fact is clearly problematic both in policy and in practice. For example, focus group respondents had either not used the phone service or tended to speak poorly of it (although two participants had positive experiences). It is difficult to generalize the problems with a low preference for e-mail. This could be the result of a lack of awareness. Focus group participants generally confirmed this, and there was a perception that it is not fast enough-even though turn-around time for both universities is twenty-four hours or better.

A conclusion to be drawn from the results on preference for reference services is that VR users have a very positive perception of VR and see the service as roughly equal in preference to the reference desk as an off-campus service. In addition, those who have used VR perceive their options for obtaining help within the library differently from reference desk users; VR is seen by VR users as a prominent option for in-library help, second only to the reference desk. The majority of focus group participants noted that, in addition to using VR from home, they had used or considered using VR while in the library. Many of the focus group participants were turned off by line-ups at the desk and preferred VR use in the library for this reason. Two participants noted the staff "were intimidating" and so preferred chat reference over a face-to-face encounter, regardless of being on or off campus. As noted earlier, Ruppel and Fagan found a significant 
number of students thought the physical reference desk staff looked unhelpful.

\section{CONCLUSIONS}

The premise for the study was based on the assumption that a reasonable exposure to newer reference services, such as chat and e-mail, had occurred, and that therefore an examination of emerging preferences for different types of services would yield helpful information for strategic planning regarding resources, services, and, most importantly, the future and efficacy of VR. Specifically, we wanted to compare reference desk users to VR users in terms of their perceptions and preferences.

The reference desk continues to be the most popular method of getting help in the library, but our findings confirm that VR satisfies a niche for some users, quite likely those who prefer to work outside the library. That said, chat reference was noted as a preference comparable to the desk for VR users when in the library. Although many users have yet to try our VR services, those who use VR tend to perceive their options for getting help differently from other users. Exposure to VR changes the perception of the landscape of reference options. Far from being a novelty, VR is seen as a significant service option for those who use it.

Our focus group participants (all of whom were solicited through VR) gave us some insight into attitudes toward email and phone reference services, but ultimately this study is unable to make conclusions regarding e-mail and phone users since these users were not surveyed. One can interpret our data as suggesting that exposure to VR appears to change the help-seeking choices and preferences for these users. Furthermore, since we found that those surveyed at the desk tended to rate all remote staff-based services less preferable than our library websites or even Internet search engines, all told, one might interpret this as suggesting that a lack of awareness regarding help options is a significant issue for our users.

Our results suggest that VR services seem to have a special appeal to graduate students. A greater proportion of graduate students use VR than the reference desk, and graduate students rate VR services higher in terms of preference for reference options than undergraduates. Our research also confirms that graduate students prefer to work outside the library (off campus, or on campus but not in the library). It seems reasonable to assume that the appeal of VR for graduate students is in large part because of the way VR is able to reach users outside the library. We recognize that the sample size for graduate students was small; therefore, these are tentative conclusions and point to further study.

The study did not attempt to explore all the reasons why users choose certain reference services over others. Rather, as a preliminary exploration, this study hoped to describe what people actually do and what they really prefer to do when they need assistance. Our comparison of VR users to desk users allowed us to make some comments about exposure to newer services and the impact that exposure may have on preference.

\section{PLANNING IMPLICATIONS}

This study has implications for the planning of reference service in academic communities.

- Virtual reference services should not be staffed by scaling back at the physical reference desk. The reference desk remains an important and prominent service even for those users who are already exposed to VR services.

- Libraries should respect and accommodate the use of VR within library facilities. VR users consider VR an important service point even from within campus libraries.

- VR services need to be promoted more heavily to reference desk users. These users do not generally seem to be very aware of the option of using VR when off campus.

- VR services need to be promoted more heavily to graduate students. VR seems to accommodate the behavior and preferences of graduate students who tend to work outside of the library.

\section{POSSIBLE DIRECTIONS FOR FUTURE RESEARCH}

Our study also suggests some future directions for research.

- A broader randomized study could look at the effect of VR services across an entire academic community or between several academic communities. Such a study could provide insight into the awareness and adoption patterns of VR by members of the community. This study could look at the preferences for reference services across the broader community.

- Further research could examine the demographics of different user groups. How do VR users compare to other types of service users in terms of their gender, age, distance from campus, disabilities, full-time or part-time status, and so on?

- Our findings suggest a relationship between preference for studying off campus and preference for VR. Kelly and Orr found a relationship between online courses and less visits to the physical library. Thus an exploration of the relationship between in-class versus online classes and VR usage would yield useful planning data to better support emerging course-delivery modes.

- Nilson and Ruppel and Fagan, as well as our focus groups, suggest negative perceptions of staff as a factor in choicemaking. Satisfaction and other qualitative measures as they relate to reference service use should be explored in more depth.

- More detail could be obtained on the needs of graduate students and similarly faculty to understand better to what extent virtual VR services accommodate these 
FEATURE

groups' specific needs.

- Expand study to e-mail and telephone users. What are the characteristics, preferences, and experiences of these users?

\section{References and Notes}

1. Marc Prensky, "Digital Natives, Digital Immigrants," www.marc prensky.com/writing/Prensky\%20-\%20Digital\%20Natives, \%20 Digital\%20Immigrants\%20-\%20Partl.pdf (accessed Apr. 19 , 2005); Diana Oblinger, "Boomers, Gen-Xers, and Millennials: Understanding the New Students," EDUCAUSE Review 38, no. 4 (2003): 37-47, www.educause.edu/ir/library/pdf/erm0342.pdf (accessed Apr. 19, 2005).

2. Prensky, "Digital Natives."

3. Kathryn M. Crowe, "Collaborative Leadership: A Model for Reference Services," The Reference Librarian 81 (2003): 60.

4. Reference and User Services Association, "Guidelines for Implementing and Maintaining Virtual Reference Services," www .ala.org/ala/rusa/protools/referenceguide/virtrefguidelines.cfm (accessed May 23, 2005).

5. R. David Lankes, Melissa Gross and Charles R. McClure, "Cost, Statistics, Measures, and Standards for Digital Reference Services: A Preliminary View," Library Trends 51, no. 3 (2003): 220-30; R. David Lankes, "Digital Reference Research Agenda," Journal of the American Society for Information Science and Technology 55, no. 4 (2004): 301-311

6. Linda Arrett and Steve Coffman, "To Chat or Not To Chat: Taking Another Look at Virtual Reference: Part I," The Searcher 12, no. 7 (2004): 49-56.

7. So Young Rieh, "Changing Reference Service Environment: A Library Review of Perspectives from Managers, Librarians, and Users," The Journal of Academic Librarianship 25, no. 3 (1999): 185.

8. Lynn Silipigni Connaway, "Physical Space for Virtual Services and Collections," portal: Library and the Academy 4, no. 4 (2004): 130.

9. For a comprehensive bibliography, see Bernie Sloan, "Digital Reference Service Bibliography," www.lis.uiuc.edu/ b-sloan/digiref .html (accessed Apr. 29, 2005).

10. Virginia Massey-Burzio, "From the Other Side of the Reference
Desk: A Focus Group Study," The Journal of Academic Librarianship 24, no. 3 (998): 215

11. Carol Tenopir, "Use and Users of Electronic Library Resources: An Overview and Analysis of Recent Research Studies" Council on Library and Information Resources, Washington, D.C., www.clir.org/ pubs/reports/pub120/pub120.pdf (accessed Apr. 29, 2005); Lesley M. Moyo, "Electronic Libraries and the Emergence of New Service Paradigms," The Electronic Library 22, no. 3 (2004): 220-230.

12. Margie Ruppel and Jody Condit Fagan, "Instant Messaging Reference: Users' Evaluation of Library Chat," Reference Services Review 30, no. 3 (2002): 183-97.

13. Ibid., 186.

14. Marianne Foley, "Instant Messaging Reference in an Academic Library: A Case Study," College and Research Libraries 63, no.1 (2002): 36-45.

15. Kirsti Nilsen, "The Library Visit Study: User Experiences at the Virtual Reference Desk," Information Research 9, no. 2 (2004), http://informationr.net/ir/9-2/paper171.html (accessed June 2, 2005).

16. Bruce Stoffel and Toni Tucker, "E-mail and Chat Reference: Assessing Patron Satisfaction," Reference Services Review 32, no. 2 (2004): $120-40$.

17. Linda Frederiksen, Joel Cummings, and Lara Ursin, "User Perceptions and Virtual Reference Services," The Virtual Reference Experience: Integrating Theory into Practice (New York: Neal-Schuman, 2004): 45

18. Kimberly B. Kelley and Gloria J. Orr, "Trends in Distant Student Use of Electronic Resources: A Survey," College and Research Libraries 64, no. 3 (2003): 176-99.

19. Corey M. Johnson, "Online Chat Reference: Survey Results from Affiliates of Two Universities," Reference \& User Services Quarterly 43, no. 3 (2004): 237

20. Our Reference Desk statistics are approximate because we compile statistics on representative weeks only rather than on a contimuous basis. Consequently the total reference desk statistics were estimated on the basis of this representative week in the fall of 2004.

21. Johnson, "Online Chat Reference," 237-47.

22. Tenopir, "Use and Users of Electronic Library Resources"; Kelley and Orr, "Trends in Distant Student Use of Electronic Resources"; Johnson, "Online Chat Reference."

23. Johnson, "Online Chat Reference."

24. Ruppel and Fagan, "Instant Messaging Reference." 


\section{APPENDIX. REFERENCE DESK SURVEY, NOVEMBER 2004}

Ryerson University and York University are studying the research preferences of our library patrons. Your assistance in filling out the following survey will help us improve our services. This voluntary survey should only take 1 or 2 minutes, and the results will be kept confidential. Your help is greatly appreciated!

1. In the last 12 months, for library-related assistance, how often have you used: (Circle which frequency applies.)

a) The Reference Desk: Never Once 2-5 times 6-10 times More than 10

b) E-mail Reference: Never Once 2-5 times 6-10 times More than 10

c) Telephone Reference: Never Once 2-5 times 6-10 times More than 10

d) Chat Reference*: Never Once 2-5 times 6-10 times More than 10

e) Library website: Never Once 2-5 times 6-10 times More than 10

e) Other_Never Once 2-5 times 6-10 times More than 10

*Ask a Librarian Live

2. If you are in the library, how would you prefer to get research help (where 1 is least preferred and 5 is most preferred)
a) The Reference Desk:
b) Telephone Reference:
c) Chat Reference:
d) E-mail Reference:

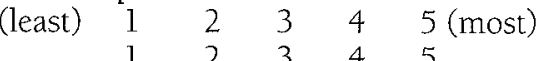
e) Information on Library website:
f) Google/search engines:
g) Other

$\begin{array}{lllll}1 & 2 & 3 & 4 & 5 \\ 1 & 2 & 3 & 4 & 5 \\ 1 & 2 & 3 & 4 & 5 \\ 1 & 2 & 3 & 4 & 5 \\ 1 & 2 & 3 & 4 & 5 \\ 1 & 2 & 3 & 4 & 5\end{array}$

3. If you are working off campus, how would you prefer to get research help: (where 1 is least preferred and 5 is most preferred)
a) Telephone Reference:
b) Chat Reference:
c) E-mail Reference:
(least)

$\begin{array}{lllll}1 & 2 & 3 & 4 & 5 \text { (most) } \\ 1 & 2 & 3 & 4 & 5 \\ 1 & 2 & 3 & 4 & 5 \\ 1 & 2 & 3 & 4 & 5 \\ 1 & 2 & 3 & 4 & 5 \\ 1 & 2 & 3 & 4 & 5\end{array}$

4. In the past 12 months, how often have you visited the library:

- A few times

- About once a month

- Once a week

- Several times a week

5. When working on an assignment where do you most prefer to do your research:

(check one)

- In the library

- On campus, but not in the library

- Off campus

- I have no preference

6. Please let us know your current status at the university:

- Undergraduate student

- Graduate student

- Continuing Education student

- Faculty

- Staff

- Other 